\begin{abstract}
Iranica
Abstracta Iranica Revue bibliographique pour le domaine irano-aryen

Volume 42-43 | 2021

Comptes rendus des publications de 2019-2020
\end{abstract}

\title{
Antonio Panaino. I nomi dei magi evangelici: un'indagine storico-religiosa
}

Christelle Jullien

\section{OpenEdition}

Édition électronique

URL : https://journals.openedition.org/abstractairanica/54157

DOI : 10.4000/abstractairanica.54157

ISSN : 1961-960X

Éditeur :

CNRS (UMR 7528 Mondes iraniens et indiens), Éditions de l'IFRI

Référence électronique

Christelle Jullien, « Antonio Panaino. I nomi dei magi evangelici: un'indagine storico-religiosa », Abstracta Iranica [En ligne], Volume 42-43 | 2021, document 26, mis en ligne le 30 décembre 2021, consulté le 24 décembre 2022. URL : http://journals.openedition.org/abstractairanica/54157 ; DOI : https://doi.org/ 10.4000/abstractairanica.54157

Ce document a été généré automatiquement le 24 décembre 2022.

Tous droits réservés 


\title{
Antonio Panaino. I nomi dei magi evangelici: un'indagine storico-religiosa
}

\author{
Christelle Jullien
}

\section{RÉFÉRENCE}

Antonio Panaino. I nomi dei magi evangelici: un'indagine storico-religiosa. Milano: Mimesis Edizioni, 2020, 150p. ISBN: 9788857574202. (Iranica et Mediterranea 4)

1 Cet ouvrage est le résultat des travaux menés par l'équipe iraniste de l'Université de Bologne, siège de Ravenne, sur la question des mages évangéliques, de leurs noms et des traditions multiformes qu'ils ont suscitées. Les noms des mages ne sont pas mentionnés dans la péricope de l'évangile de Matthieu (2,1-12), mais ils ont donné lieu à des traditions apocryphes qui ont cherché à les nommer et à détailler leur nombre, parfois en fonction des présents apportés à l'enfant Jésus, souvent en les démultipliant. Le volume se présente comme une enquête préliminaire sur les origines de cette tradition onomastique attestée dans différentes langues et cultures d'Orient et d'Occident de l'Antiquité tardive et du Moyen Âge. L'A. envisage de réaliser un Namenbuch dans les langues et littératures de cette vaste aire géographique, comme l'appelait de ses vœux Dom Henri Leclercq dans le Dictionnaire d'archéologie chrétienne et de liturgie en 1931. Il souligne dans cette introduction ("I nomi dei Magi evangelici. Considerazioni storico-linguistiche e storico-religiose intorno ai nomi dei Magi evangelici : Prolegomena ad un Namenbuch") comment, à l'analyse, les mages sont finalement perçus 1.- soit comme les garants d'une sagesse étrangère universelle ; 2.soit comme la personnification d'astrologues, héritiers des Chaldéens et membres du collège sacerdotal, à l'origine de traditions dont les prolongements mystiques et ésotériques sont multiples ; 3.- soit comme des zoroastriens attendant avec ferveur la venue du Saošyant ; 4. - soit comme le vrai roi du monde et messie, en une transposition sur des personnages illustres tel Cyrus par exemple. L'A. souligne que la figure des mages évangéliques et leur promotion ont sans nul doute formé un important moyen de dialogue interculturel entre la communauté chrétienne et les membres d'autres 
religions avec lesquels elle était en contact. Comme précisé dans le prologue, une partie du matériau de ce volume avait déjà été publiée dans le huitième volume des Atti del Sodalizio Glottologico Milanese (nouvelle série) de 2013 (parution en 2016), p. 41-82. Trois contributions viennent enrichir le volume: une étude en Appendice par P. Ognibene présente la tradition ossète du passage néo-testamentaire sur les mages. Deux courts essais développent des aspects ponctuels de la thématique. Le premier, par A. Gariboldi (Université de Trieste, Italie), fournit une étude consacrée aux sources numismatiques indo-parthes relatives à la dynastie de Gundafarr, dont le nom a été associé en Occident à la figure du mage Gaspar. Le second, par J. Kotyk (Université McMaster, Hamilton, Canada), réunit les témoignages chinois relatifs aux mages évangéliques et analyse la réception de l'image des mages évangéliques en Chine. Des tableaux synoptiques des noms des mages réalisés par A. Zubani seront des instruments appréciés pour des travaux futurs d'onomastique ou d'histoire. Pour les sources syriaques, des tables partielles avaient été éditées à partir d'un relevé systématique par P. Gignoux et C. Jullien, «Les mages christianisés. Reconstruction historique et onomastique des listes nominales syriaques ", dans A. Amir-Moezzi, J.-D. Dubois, C. Jullien et F. Jullien (éds.), Pensée grecque et sagesse d'Orient. Hommage à Michel Tardieu. Turnhout: Brepols, 2009, p. 323-346., et «Une question de parenté autour des rois mages ", Studia Iranica 43, 2014, p.99-109; par M. Debié "Suivre l'étoile à Oxford, inédits sur la venue des Mages", dans G. A. Kiraz (ed.). Malphono w-Rabo d-Malphone: Studies in Honor of Sebastian P. Brock. Piscataway, NJ : Gorgias Press, 2008, p. 111-133.

\section{AUTEURS}

CHRISTELLE JULLIEN

CNRS, CeRMI, Paris 